\title{
MIRADAS CRUZADAS
}

Inomor MIIIINO

Unis. complutonsio

\section{RISSUM:}

En las literaturas fiancóonas (la del Magrob, Alrica y ha do las is]as del Caribe y Guatanas que hoy tratamos), la longua va a constituir, junto con la colonizacion, la mityor obsesion tomética do estas literaturas. ¿Y por quo la lengua", l'orefue es la que preside el mismo destino de estas litcraturas francólonas que hán nacido dentro de una grave y especílica conyuntura, en el curso de la llistoria: violación de la momoria de un pueblo al quo

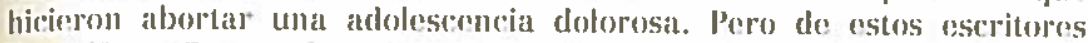

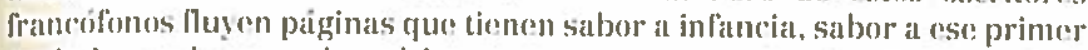
macimionto de una algarabia sonora, pájginas que sirvon. Lambién, de votaculo cou col conocimionto de esas socicelades aborígenes.

\section{SUMMARY}

In Fronch Iticratures these of the Maghrob, Arica and those of the Caribboan and Guayana s islands that wo stucly todayl, tho language goes to constitute, joined to the colonization. the main thematic obsession of these hiteratures. And why the language? Becatrso it is the one which presides over the same fate of these lonoh literatures which were born inside of a critical sperilie juncture, in the courso of Ilistory: violation of the Poople's memory forcing it to abort a painfut adolesconce. But from these lirench writers llow pages which bave a childhood lavour, a llavour to this first birth of a sonorous gabble, patgos that serve, too, like a way in the knodwledge ol theso indigenous sociatios.

\section{INTRODUCCION}

Fil lianés no es sojlo la longua de los franceses, en liuropa y on varios continembes es lengual materna. lengua nacional, longua ojjejal, sogunda lrogua o longua de ocio. Si an al siglo XIX, et geógrafo Onósimo Reclus emptró al termino francophonies, hoy, la mayoría do los países, habjendo tomacto ya ca sus manos sus propios destious, usto termino so ha llegado a impouser, signilicando que la lengua limancesa no as ni longua muerta ni propicalad axclusiva del lirancess. Ylo que es todavia mis importante, es que. debido al doseonorimionto do hermosas longuas matornas aborjgenes reptartidas por al Univorso, la lenguth lrancosa sirve do vohículo an ol councoinionto do esas socicadados.

Jin al caso det Magrob, por ejomplo, si la longua árabe reprosenta ha itutonticiclad y la todigrión, $y$ la lengua borober revela la iclontidad profunda del sere, la lengua francesa que simbotiza ol aceoso a la modernidad, confiero 
una mirada distante y una conciencia crítica de la propia cultura. Pero la ambigüedad de la lengua lrancesa en el Magreb, como en la mayoría de los países Irancófonos, y la polémica, que ha derramado ríos de sangre y tinta, alimenta una paradoja. La lengua extranjera encarna la alienación en la cultura del Otro', al mismo tiempo que ofrece el instrumento intelectual de una posible liberación y el enriquecimiento de universos culturales diferentes que se encuentran, que se confortan, que se soportan y que se enriquecen, pero, en cualquier caso, la dualidad de dicha contradicción sigue estando en pie, puesto que la connotación de «tengua» lleva ya intrínseca una gran carga ideológica:

r'Tout peuple colonisé, [...] ]est-à-dire tout peuple au sein duquel a pris naissance un complexe d'infóriorité du fait de la mise au tombeau de l'originalité culturele locale, se situe vis-à-vis de la nation civilatrice, c'est-ì-dire de la culture civilisatrice.. ${ }^{2}$

lin la medida en que Francia se aproxima a una realidad temporal, espucial o científica, bien sea en cl Magreb, en Africa, en Bruselas o en el Quebec, su lengua va a ser la más empleada, pero también la de mayor motivo de desprecio puesto que representa al país de dominación.

\section{MAGREB}

Preocupandose por su buen renombre, de apertura al mundo y de solidaridad internacional, [irancia aporta su concurso a los países extranjeros que lo solicitan en el terreno económico, tecnológico, cientifico, así como cultural, on un sentido vasto y estricto.

A la cabeza de todo un disposilivo cultural del Estado, se encuentra el Ministerio de Astuntos extranjeros, lo que no excluye que otros Ministerios tengan tambión responsabilidades hacia un cierto número de países extranjeros con asuntos como Cooperución y Desarrollo, Comercio exterior y Francofonía. Hace ya tiempo que las misiones, sobre todo las católicas, debido a su mayor número, contribuyeron a la difusión del francés en el mundo -pioneras a un mismo tiempo de la fe- hasta las tierras más confines del Universo.

Ha pasado ya mucho tiempo-aunque hoy resuenen los ecos de la que fue una encarnizada guerra- que la metrópoli en el Magreb, queriendo siempre "allrancesar», creó escuolas gratuitas como consecuencia del decreto de 1883 de Jules Ferry. Ya el "Plan de estudios» de 1889-1890 decía al referirse a la Historia:

"Los escritores magrabies de lengua francesa, acseritores colonizados", que contraponen su cultura a la de Occidente, su imaginario está puesto siempre en el Otro: al'autre des arabes $c$ 'est l'Occident. C. C. Laroui, A., L'ideiologie arabe contemporaine (préface do Maxima Hodinson), Paris, Maspéto, 1967, p. 15.

${ }^{2}$ Fanon, I’.. Peau noire masques blancs, París, I.e Seuil, 1952, p. 14. 
al̃n confondant leurs intérêts avec les nôtres. tes Indigènes partagent avec nous l'héritage du passé; nos ancêtres deviennont les leurs. $n^{3}$

En un principio, la mayoria do las familias temiendo que sus hijos se sintieran inlluidos por la cultura extranjera, se despersonalizaran, y su propia cultura árabe y musulmana se perdicra, rehusaban enviarlos a la escuela francesa (à l'erntré de la gueule du loup ${ }^{+}$, dirá Kateb Yacine) como sucedió con la creación de las primeras escuelas para mujeres, que Fadhma Aît Mansour Amrouche describe en su sencillo y sincero lestimonio, /istoire: de ma vie ${ }^{5}$.

$Y$ es que las lenguas son cuerpos, cuerpos sordos, cuerpos extraños uno a otro, como dice la investigadora Shoshana Felman quien ha sabido situarse en la encrucijada de las lenguas:

“Elles se traduisent l'une dans l'autre, mais foncièrement no s'entendent pas.»"

Con lo anteriormente expuesto, vemos hacerse realidad ol siguiente proverbio francés bien conocido:

«Quand les Portugais colonisent, ils construisent des églises; les Anglais construisent des comptoirs de commerce et les Français construisent des écoles.»

lìn efecto, en la colonización latina, la lengua - «angre de la raza»desempeña un papel primordial, al que al italiano correspondo el carácter jurídico, al firancés la diplomacia, y al español la mística.

Para comprender bien la problemática de la lengua lrancesa, que reposa en un doloroso matiz político y religioso en el Magreb, hay que aceptar -sin mirada curopea- que sólo Marruecos, contrariamente a lo que sucede en Argelia, se basa en tres grandes principios traducidos y plasmados en la siguiente y excelente divisa: "Dios, Patria. Rey".

Esta particularidad es, verdaderamente, la que distingue a Marruccos. sobre todo, do los demás países musulmanes: la presencia a la cabera dol pueblo de un «Comendador de los Creyentes\%. Por lo tanto, en lases críticas Jistoriticas, la nación marroquí se sostiene y alianza en el cimiento nacional que lue ol Islam. İ́n todo momento crítico, dramático, ol Sultán no es sỏlo un jele de listado -ta] y como lo entiendo el europeo con mirada limitada-

${ }^{3}$ Déjeux, J, La Littérature Maghrothin? d'urpression française, Que sais-jo? P.U.F. 1992, p. 11.

4acine, K, Le Polygone ćtoils, París, Le Souil, 1966, p. 182.

Ait-Mansour Amrouche, IF, Wistoire de ma vie, l’aris, Maspero, 1968, pp. 31

yss.

Felmant. S., Le sacandale du corps parlant, Paris, Lo Souil, 1980, p. 118. 
sjuo que permanece, por encima de todo, suceda lo que suceda, a lo largo do los avatares de la Ilistoria, como kjele espiritual» incontestable.

I Jasian It, monarca marroqū̄, deplorí que la cuseñanza y la adminis. tracion lueran systematiouement francisees durante ol Protoctorado, asj (o)mo que sus més lieles seguidores liubjeran aprendido la lengua lrancesa: non pas au lycée ou à l'universilé, mais dans les prisons on en exil ". Sin ombargo, a pesar de tanto desmán. considera a la lengua francesa como una gran ventana abierta al mundo:

(ll n'est pas possible de connaître la langue liançăaje sans l'aimer. Jille a été depuis des sieciles, le vihieule d'idénes libérales et ginocircuses. C'est une f'enêtre large ouvorte non seulement sur le mondo occidental, mais sur colui do la logique, de la raison ef de la mesure., $)^{\text {th }}$

l.os países del Magrob permanecon y pueden permanecer largo tiempo dotados de esa gran perouliaridad que es el bilingiaismo. J'oro será solboe todo por ese cauce riquísimo de la lengua y del pensamiento, por el que estas dos civiljzaciones contimuarán reoncontrándose. Ya on 1970, declaraba l lassan II al comentar este problema en Le Petil Marocain:

"La connaissance parlaite des langues étrangères pormettra d'enrichir notre patrimoine arabo-musulman, s

Desde esta visión universalista, respetindo ol propio código personal y la propia identidad, muchos son los escritofos que desean aunar una cultura plural, dar una visión cosmopolita -como por ejemplo la de un Magreb plaral" - que rocoja todas las tendeveias culturales confundidas, ponsaniento pluril que libera al escritor, al mismo tiempo que cimienta su identidad.

La pensée de la différence es, on oste caso, la única posibilidad de alcanzar esta reconciliación, de resolver este conllicto milonario entre Oriente y Occidente que se labia convertido, a través del tiempo, en mutuo desconocimiento.

"La dinastía alauita, quo actuatmente roina en Marrumos, ns originaria de Arabia y mis exactatuente de la rogion de Yanbo, en el lejaz. Las alauitas. como sus predecesores Ios sabianos, son jeriles, descendientes do Jassan, hijo do Játima. quion a su vez lo fuo del Profota Nohamed, y do Ali yorno de císto. Do ahí que sean tambión designados bajo le nombri de hassanianos, puesilo que procodon do lassan.

*Hace exactamonte cien años on 1894, su antrocesor alauita llassan [ -que Lodos los viajeros europeos raveuerdan y doseriben cono un buen soluerano- moria sur

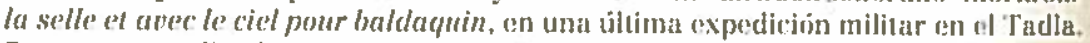
Su rotrato realizado por Thóo van liysselberghe expresa una infinita trisioza. ronforme al astado des su imperio, al que logro mantesere dontro de una relativa paz. toniendo que acoptar qur ara Europa quien ganaba y sabiendo que Charlas de Foucauld quería donner le Maroc à Jesus et à la lrance.

"Hassan II, Le dijf, Paris, A. Mticluol, 1976, pp. 112-13.

"Khatibi, A. . Waghreb phuriel, París. Denoül. 1983. 
Pero, en un priscipio, deuál iba a ser la imagen do lerancia en la Literatura Fiancólona -sobre todo on ol Magreb- sino metafora de la atrayente ciudad -que jndiferente, orgullosa levantó una cru\% en cl corazion del musulmán- así como la hermosa mujer extranjera opuestal at lat otra virginal??

Rebosan los lextos de imágenes obsesivas y alienantes. De lorma genceal, al superego del Otro es con frecuencia ol superego lemenino. Las descripcionesy ensoñationes que jallonan las numerosas obras sobrepasan el rstadio do la pura intención o invención estética. puesto que se arraigan. con frecuencia, en la experiencia mas trágiea $y$, a veces, en la monos confesable. It novelista, en un primer monento, resuelve su tensión en la lengua. ma la mujor extranjeray en la ciudad por medio de un ejorcicio caltijetico como os ol de lat escritura. $\Delta$ héroe, le lascina al prestigio de ambas y lo consigue por medio de ala violencia del textom, sugestivo título de la interesante obra de Mase: Gontard".

Asi, desde la "Therise codiciada par Miliani en Zhora, la femme du mineur, las atrayentes tarjetas postalos francesas clavadas en la pared que Mokrane absorbe con la mirada en Les Chemins qui montent de Mouloud Farauus, el hechizo de la rubia surgida de un sueño nómada para Djamal de llemri Króa, ol inolvidable bóroe-narrador de le Passé Simple de Driss Chraibj, quien, en viva sinestesia de vision, tacte y olor, aspira la cascada rubia y se aúna al héroe de Un été africain de Mohammed Dib, al sueño erótico y solicto de Céline en La Répndiation de Rachid Boudjedra, a la imagesl renacentista que es María en La statue de sel para Albert Memmi (1) al Lartansudo Mhezzin (muez=meet, zin=sainl) de Mourad Bourboune, errante, desaraigado que descle su llegada a laris va en bisqueda de Pigalle $y$ de Montparnatsse. Todis, todas las heroinas de los primeros textos son, como la ciudad y como la lengua francesa, a tractivas y deseadas, puesto quo como aljrma $A$ dbdallah Memsnes:

"la comnaissance de la langue - des langues- constitue un acte d'amour.»'

Lat mujer, debido a su porte y maquillaje. Lil ciudad, debido is su luz y espectáculo. Y la escritura, por haber sjdo realizada en un margen esquizoide; pero ambas lo f'ueron, jay!, a veces, inalcamables.

11 heroo, decepcionado, ya había sido advertido por medio de los consejos del "Señon" en la obra pionera del Magreb do Driss Cliraibj, Le Passe'. Simple, que marco el recliazo a los onjgenes, si, pero que tambien lue

"Gontard, M., Molence dir texte. La Lillerature marocaine de langue.

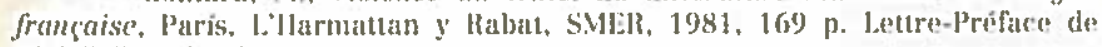
Alodulkribir Kluatilui.

Tmaginaires de lantre, Shatbi el la mémoire litteraire. Paris. L'I larmattan, 1987. p. 4.5. 
crítica acerba y desprecio insultante a Occidente: «liancia es el burdel del mundo y el retrete de ese burdel es París.»

A pesar de todo, a pesar de las criticas y del necesario retorno a la tribu para sanarse, para confundirse en clla, pour sé refaire une âme complète -según Maurice Barres- las Literaturas l'rancófonas desean mirarse, en general, en el espejo de la Capital del corazón europeo.

\section{ISLAS CARIBEÑAS Y GUAYANA}

Llamadas de diversa forma (Indias occidentales, debido al nombre que se dio en un principio al viaje de Colón; Caribes, por el nombre de una de las naciones que las ocupaban antes de la llegada de los españoles; Antillas, por el nombre de "Antilia», isla misteriosa situada al oeste de los mapas más antiguos realizados por Tolomeol. este exótico rosario de islas siluadas en el golfo de Méjico, comenzó a existir para la civilizaclón occidental con el descubrimiento de Colón. en 1492, al abordar las costas de Santo Domingo en el centro del archipiélago. Un año más tarde, el intrépido viajero genovés a bordará Guadalupe. Las orillas de la Guayana serín exploradas en 1499. En 1502, Colón, en su último viaje, descubre La Martinica. Ingleses y franceses ocupan las islas al mismo tiempo que los españoles.

Los primeros testimonios del país y de las costumbres de los colonos, de los "salvajes» y de los esclavos, se debe a la pluma de los misioneros envíados a otorgar el bautismo a la mies de convertidos, que fueron arrancados, según ustos mismos misioneros, "al infierno del paganismo", «infieles» quc, en compenstción, dieron azúcar para aendulzar» a toda una Europa hambrienta. Aún lioy, en el folclore antillano, la figura del padre labal. misionero domiricano, sigue siendo aquel ogro lejano con el que la madre amenazaba al niño desobediente. No es inútil recordar que las primeras letras de la literatura de las Antillas fueron impresas con hierro candente en el pecho de los esclavos.

“|... les anciens renouvellent toujours leurs plaintes et animent les jeunes à se souvenir des luumanilés... comme les Français pareillement sont venus prendre leurs terres, ont luci leurs parents, et on massacré leurs amis et ces vicillards et vieilles Sauvages allument tellement le feu, la colère et la haine dans lo coeur des jeunes barbares, que grinçant des dents, pleurant de rage et de furie entendant ces contes... ils ćclatent d'un cri épouvantable: «Nitoüarmeen homan niralinin...»" ( $A$. Chevillard, chap. IV)

Es dificil imaginar, con mirada actual, el impacto intelectual que debieron soportar astos hombres hace casi duscientos años en la gran colonia lrancesa de las Antillas, en una guerra por la independencia que duró doce años, desde 1791 a 1804, pero eso es ya anúlisis del historiador y del sociólogo, puesto que en literatura fue el aborigen quien, en 1935. 
alrededor de la revista l'ḱtudiant noir ${ }^{1: 5}$ fue al reoncuentro de un grupo de hombres sensibles que lanzară is la negritud: Aimé Césaire, martinico, con la creación de esta palabra, Léopold Súdar Senghor, senegalés, con la dolínición de su ideologia y leéon Gontran Damas. guayano, a través do la materia poética. En electo, Damas, como mestizo dolorido, reivindicará la negritud desde lo más profundo de su ser, en 1937, con la primera poesía que lleva el hermoso título de Pigments. En 1939, en la revista Volontés, Aimé Césaire publica Cahier d'un retour au pays natal. Texto que no será descubierto hasta que Andrë Breton llegue a La Martinica en 1941. Los tex tos de Césaire de poderoso lirismo, dotados del impulso de la visión épica de la pasión de toda la raza negra, encontraron un cco entusiasta en las dos orillas del Ataintico - desde las Antillas a Africa- en una época en la que ambas se despertaban del dolorido sueño para ponerse en búsqueda de su identidad:

«Ma bouche sera la bouche des mallseurs qui nount point de bouche, ma voix, la liberté de celles qui affaissent au cachot du désespoir., ${ }^{14}$

la generación posterior a la Segunda Guerra Mundial lue brillante y lecunda, y lo mismo en las Antillas lrancesas que en Haiti se desarrolló una literatura de combate que supo llenar de lirismo todas las vibraciones del corazón de un pueblo humillado. La lengua, dominada y poseída, se plegó a la generosidad do la inspiración sirviendo a la expresión brillante de pensamientos poderosos e innovadores. La literatura antillana tiene mucho que decir. Frantz Fanon fue el portador más lirme, el que amalgamó la belleza de una relórica elicaz a la pasión elocuente y a la razón discursiva. Pero una vez superado el recurso a la imitación, como sucedió en el Magrob, la literatura antillana encontró su novedad y su propia diferencia frente a Francia, como dice Salvat Fitchart en le Monde tel qu'il est (1967): Notre différence n'a pas beaucoup d'épaisseur... C'est juste une couche de peinture. Pigment on appelle ça.

En 1992, "el premio Goncourt» lue concedido al martinico P'atrick Chamoiseau, por su novela Texaco (nombre de la ubicación de las cubas de almacenamiento de la sucursal antillana de la gran compañía petrolífera). que narra por modio de una voz l'emenina la creación de un barrio de chabolas y de latón en la periferia de Fort-de-France. Chamoiseau, criollo, obtuvo ya en 1991 el primer premio Carbet por Anlan d'enfance. Al año

13 "La publication des ótudiants antillais -martiniquais devrait-on dire *tu vu des signateres- s'appele maintenant I'Fudiant Noir. Elle n'appartient pas à la filiation politique Revue da Monde Noir/Legitime Deffonse, mais nu monde du syndjoralisme lycéen ot étudiant antillais de Paris." Antoine, R., Liteérature francoantillaise, Paris, Khartala, 1992, pp. 176.77.

${ }^{14}$ Coisaire, A., Présence Africaine, Paris, 1956, p. 42. 
siguiente, fue concedido también «el premio Frantz Fanon» a un hombre tercermundista convencido, que consagró su vida a la defensa de les damnés de la terre: al abogado Marcol Manville por su ensayo Les Antilles sans fard. Fin Guadalupe, las ediciones Jasor publicaron Héritage de Caliban, conjunto de estudios consagrados a los diferentes escritores antillanos que se sitúan en la estela de Aimé Césaire.

El último resorte de esta literatura, bien sea pintoresca, histórica o polémica, es una protesta, en la que se consume, para persuadir al mundo de que este lirismo está escrito por el Hombre. El receptor queda impresio. nado por los temas perennes que atañen la justificación del ser antillano, por la exaltación de su semejanza o de su diferencia frente a Francia.

\section{SOL AFRICANO}

Literatura negroafricana, literatura negra de expresión francesa. Si se mantiene el axioma por el que a una lengua le corresponde una cultura especílica, vemos que esta amalgama de términos (referida a la grafía de escritores de raza africana que se expresan en una lengua que no es la que mamaron de unos pechos negros) indica, desde un primer instante, una ruptura: el nacimiento de una literatura problemática:

"Littérature africaine», "littérature maghrébine»: dans les deux cas un ensemble de textes est défini à partir d'une identité collectlve, à référence géographique. Dans les deux cas il s'agit d'une identité qui se construit, contre l'ancienne négation coloniale, mais dans la langue de l'ancien colon comme dans ses normes littéraires: non seulement ces littératures sont "de langue française" mais elles s'affirment par le genre romanesque, dont la tradition fut longtemps européenne.m.15

Africano, ärabe, francés, francofonia, identidad, lengua, literatura, todos estos términos son también del Magreb.

«... sentez-vous cette souffrance

Et ce désespoir à nul autre égal

D'apprivoiser, avec des mots de France

ce coeur qui m'est venu du Sénegal?

\section{Léon Laleau}

No se deberían olvidar estos versos. Nunca deberíamos ignorar el conflicto que se desprende de estos versos y del que los distintos estudios sobre la francofonía no cesan de hablar, Cumo fueron los anälisis de Frantz Fanon en Peaunoire, masques bancs, y los comentarios de Jean-Paul Sartre

${ }^{5}$ Bonn, Ch., Ecritures croiseies. Lectures croisées. Coordination Abderrabman Tenkoul, Arrique Orient, 1991, p. 21. 
en "Orphée noir»" , en la Anthologie de la nouvelle poésie nègre et malgache dirigida por Léopold Sédar Senghor, primor presidente de la República del Senegal, ensayista, poeta, padre de la negritud y primer africano quien, en 1935. tras su memoria sobre $L$ 'Exotisme de Baudelaire, obtuvo lin agregaduria en la Universidad y lue iniciador del movimiento de la francofonía, palabra que ól mismo consagró.

Sengor fue pionero en reivindicar la independencia para su país como lo fue en el elogio de la francofonía que así la definió:

"Ce n'est pas, comme d'aucuns le croient, une «machine de guerre montée par l'impérialisme français». Nous Sénégalais avons été parmi les promières nations africaines à proclamer et à pratiquer [... [ notre volonté d'indépendence, au besoin "par la force» mais, en même temps, notre volonté d'entrer dans une communauté de langue française. [...] Et si nous avons besoin de plus d'assistants techniques francophones de haute qualification, c'est qu'avant tout. pour nous, la Francophonie est culture.p 17

Los africanos, como todos los colonizado para no sor del todo subyugados, llegaron a dominar la lengua del poder (a través de lá lengua francesa, arma milagrosa) y dejaron oír a un mismo tiempo su dolor acompañado de su reivindicaciones. En Senegal, por ejemplo, cuna de Senghor, a partir de 1920, las autoridades se preocuparon para que los africanos se arraigaran en su propio terruño. Fuc, entonces, cuando Césaire, con su manojo de poemas, Cahier d'un retour au pays, enarboló lieramente el insulto "negrom. Vocablo que, entonces, sirvió de entrañable adhesión al grupo de afroantillanos. Ignominia echada en cara a Francia y a Europa, como ya vimos, debido al pigmento de la piel. Protesta que se apoyaba en cuatro siglos de deportación de esclavos africanos por los comerciantes árabes y curopeos, tras deconios de colonización ęn Africa y, en consecuencia, la creación, por parte del colono, de una lïme ideologja racista que impregnó todas las fibras de la psiquis europeit.

Ën sus discursos De la négritude y La négritude est un humanisme, Léopold Ségar Senghor desarrolla una negritud metalísica que corresponde u una muy delendible teoría filosófica de lo irracional. Los ejemplos que expone engloban al arte negro, pero tambirín a los fillósolos presocráticos, Bergson, Heidegger, Teilhard de Chardin, Matisse así como a la poesia surrealista. EI reencuentro de los dos mundos cra irreversible, el africano

${ }^{16}$ Surtre. J-P., "Orphée noir", Anthologie de la nouvelle poesice nègre at malgache. Lépold Sédar Senghor (dir.). coll. «Art et Ijtterature n 1, París, Presse Universitaires de France, 1948, pp. IX-XXIV.

${ }^{17}$ Tétu. M. (Senghor, L. S., Discours à l'Universié Laval, 24 septembre 1966), Lafrancophonie. Histoire, problematique, perspectioes, Paris, Hachette, 1988. Próface de $1 . .5$. Senghor, p. 67 . 
y el europeo tenian que reencontrarse. De ahí que Senghor hable de mestizaje cultural en su poesía intentando alcanzar un acentro», el más místico y el más lísico entre las culturas (l'union centre à centre de l'âme avec l'âme, dans la joie de la beauté. c'est-á-dire de la vérilé enfin embrassée ${ }^{14}$ y que el caballero de l'Aven $u$ cre ambiguë de Cheikh Hamidou Kane diga a su amigo Lacroix: nul ne peut plus vivre de la seule préservation de soi. Permanecer fiel a su cultura negando la evolución inducida por la colonización o traicionar a su pueblo, ésa es la disyuntiva entre fe y conocimiento: el mundo de la tradición transmitida por la escuela coránica $y$ el mundo occidental metonimia de la escuela francesa; «aventura ambjgua» de varias generaciones de africanos, "angustia por no ser dos», al mismo tiempo que invita al lector a una profunda rellexión sobre la condición humana.

Reencuentro y búsqueda de un nuevo saber que marcará profundamente a todos los jovenes intelectuales por Europil y sobre todo en Francia. lieencuentro que alimenta a más de un escritor en el tema del exilio y del desarraigo y que lleva a la afirmación de una identidad cultural africana. Ya André Gide despertó la "mala conciencia» del colonizador cuando publicó, on 1927, Voyage au Congo, y, en 1928, Relour au Tchad. Sin embargo que un negro denunciara el colonialismo no podía ser aceptable. Circunstancia que sucedió cuando, en 1921, el antillano lené Maran, detentando un cargo político, publica Batouala, obra que obtuvo el premfo Goncourt, pero que, en contrapartida, el autor tuvo que renunciar a sus funciones administrativas. La obra de Maran tenía la imprudencia de poner en boci del negro procedimientos lúcidos, y con ello desencadenar un escándalo que hoy apenas se puede imaginar". Pero como afirmó Césaire en Discours sur le colonialisme, este «grito negro», cogido on delito flagrante por su plena lucidez, no convenia a la norma establecida por lo que era urgente hacerlo silenciar. līn la historia de la época colonial abundaron los ejemplos do osa naturaleza, y fue comprensible que la escritura poética estuviera bañada en violencia.

Pero ya desde las primeras publicaciones, se constató la preocupación por introducir al Otro en la esencia de lo africano, en tratados que pueden ser calificados de etnológicos y filológicos. Tras la S.G.M., al grupo inicial fundador de là "négritude» (del que formaba parte los senegaleses Socé Diop y Birago Diop premio del Africa negra 1964 por Contes el Lavanes ${ }^{20}$ ), se unió otro grupo de poelas, los antillanos Tirolien y Niger, el malgache Rabemananjara y el senegalós Alioune Diop (fallecido en 1980), con el fin de afirmar, en el París de 1947. su identidad en la revista Présence africaine que se completará con la editorial del mismo nombre y desde donde 50

"Ecribains de langue française, n" 82, janvier-mars, 1986, p. 36.

"Liltérature franco-antillaise, op., cit., pp. 154-65.

${ }^{20}$ Ver el emocionado articulo, "Lettre à Birago Diopm. Francofonia, Universialıd de Cádiz, n*2, 1993, pp. 181-86. 
expresarán jóvenes talentos. Ya desde la tribuna de esta revista novelistas, poetas y ensayistas, Camus, Sartre, Madaule, Lanza del Vasto, y tantos otros, quisieron, con gran voluntad, trabajar paciente y amistosamente por el acercamiento de todos los pueblos. Al año siguiente, la poesía de Senghor, Césaire, Damas, Diop, Rabemananjara, será ensamblada en Anthologie de la nouvelle paésie nègre et malgache de langue française, precedida de Orfeo Negro, prefacio de Sartre, auténtico "monument historique» que marcó el primer hito fundamental en el nacimiento de esta literatura. Desde entonces al dia de hoy, con Littératures en langues africaines y Littérarures et écritures en langues africaines, ha quedado mas que demostrado que la literatura africana permanece viva y que su cuerpo, tatuado con la huella de la palabra, es un rico texto oral enriquecido con palabras llenas de miel. con miradas y silencios prolundos, en un hermoso guiño eterno con el Universo.

Este encuentro de culturas era ya la luente del progreso para Birago Diop. El empleo de la lengua francesa no le planteó problema alguno: «el alma negra puede introducirse, opinaba, en la lengua de Verlaine o de Voltairem, Por sus cuentos, como por los de tantos otros escritores, corre el espíritu intimo de su pueblo. Oralidad recreada que permitió que naciera al mundo moderno.

Sin embargo la lengua impuesta por lerancia, motivo de gran reserva, no debe modificar la sociedad despersonalizándola y provocando la muerte de la Jengua autóctona, como se dolía Rabemananjara:

"Le lirançais est un instrument de pouvoir dont se sert une cilite pour tenir à l'écart la population dont il détruit les particularismes et provoque une certaine uniformisation. La lrancophonie serail un espace qui laisserait s'allirmer le polyformisme des peuples, un carrelour où se rencontretaient les particularítés pour s'enrichir mutuellement. Hélas! Entre les discours et la réalité, il y à un fossó. le français tue nos langues.s?

\section{CONCLUSIÓN}

En las literaturas francólonas, la lengua va a constituir, junto con la colonización, la mayor obsesión temática de estas literaturas. El lugar quo ocupara también la madre con los temas que se derivan -la infancia, la tradición, la oralidad. la condición femenina, la relación hombre y mujeren estas sociedades plurales, junto con la que ocupa la colonizacion con sus torolarios como fueron las guerras de liberación y, en especial, la relación del colonizador con el colonizado desembocaraín en la búsqueda de una identidad mutilada.

¿Y por qué la lengua? Porque es la que preside el mismo destino de estas literaturas francólonas que han nacido dentro de una grave conyuntura

"Rabemananjara, J., Le Detoir, Comores, 21 juin 1986. 
especílica, en el curso de la historia: violáciún de la memoria de un pueblo al que hicieron que abortara una adolescencia dolorosa.

De todos estos escritores francólonos que han tomado prestadas algunos vocablos ilícitos a la lengua del Otro, lluyen textos que tienen sabor a infancia y a ese primer nacimiento de una algarabía sonora.

Puesto que escribir en la lengua del Otro no es olvidar el origen, es alejarse un tiempo de la tierra natal, es alejarse un instante, a la laz de la luna, del arruyo materno, es habitar el nombre propio como lo hizo el alma del guadalupeño Saint-Jolın Perse, es estar mís allí de cualquier país, de toda causa, y sin embargo, presente en cada propio país, transmutado y disfrazado en la lengua que lleva al escritor, que lo reconforta, lo soporta y que el escritor ama y detesta. 


\section{BIBLIOGRAFIA}

Magrcb

- AîT-Mansour amRouche, F., (1968) Histoire de ma vie, París, Maspéro.

- BounbounE, M. (1968) Le Muezzin, París, Bourgeois (agotado)

- CHRAÏBI, D. (1954) Le Passé Simple, París, Denoël (folio 1728).

- DEJJEUX, J. (1992) La Lillérature Maghrébine d'expression française, Que sais-je? P.U.F.

- DIB, M. (1959) Un été africain, París, Le Seuil.

- FELMAN, S., (1980) Le scandale du corps parlant, París, Le Seuil.

- FERAOUN, M. (1957) Les Chemins qui montent, Paris, Le Seuil.

- GONTARD, M. (1981) Violence du texte, París L'Harmattan.

- HADJ HAMOU, A., (1925) Zhora, la femme du mineur, París, Monde moderne (agotado)

- Ilassan II, (1976) Le défi, París. A. Michel.

- KIIATIBI, A. (1983) Maghreb pluriel, París, Denoël.

- KREA, H. (1961) Djamal, Paris, Calmann-Lévy.

- LAROUI, A., (1967) L'Idéologie arabe contemporaine, Paris, Maspéro.

- MliMMI, A. (1953) La statue de sel, París, Buchet-Chastel (Gallimard 1966; I'olio 1972).

- MEMMES, A., (1987) Imaginaires de l'autre. Khatibi el la mémoire litléraire, Paris, L'Harmattan.

- RACIIID, B. (1969) La Répudiation, París, Denoül (1985).

- YACINE, K. (1966) Le Polygone étoilé, París, Le Seuil.

Caribe, Guayana y Africa

- BONN, Ch., (1991) Licrilures croisées. Lectures croisces. Coordination Abderrahman Tenkoul, Afrique Orient.

- Cĺ́SAIRL: A. (1950), Discours sur le colonialisme, París, Présence Africaine; 1970 (poche)

- CÉSAIRE, A. (1956) Cahier d'un relour au pays natal, Paris, Présence Africaine; 1971 (poche)

- CliAmolseau, P., (1992), Texaco, París, Galtimard.

- CHEIKH, HAMIDOU K., (1961) l'Aventure ambiguë, París, U.G.E., 1971; $10 / 18$.

- DAMAS, 1..-G., (1948) Poètes d'expression française. París, Le Seuil.

- DAMAS, L.-G., (1966) Pigments, névralgies, Paris, Présenee Africaine.

- DIOP, B. (1964) Contes el Lavanes, Paris, Présence Africaine; 1973 (poche).

- Ĺcrivains de langue française, (1986) $\mathrm{n}^{\circ} 82$, janvier-mars.

- FANON, li.. (1952) Peau noire, masques blancs, París, Le Seuil.

- FANON, F.. (1961) Les damnés de la terre, l’aris, Maspéro.

- GERARD, A. (1992) Litlératures en langues africaines, Belgique, Mentha. 
- MAGNIER, B., (1993) «Lettre à Birago Diop», Francofonia, Universidad de Caidiz, $\mathrm{n}^{* 2} 2$.

- MARAN, R., (1921) Batonala, Prix Goncourt; (1938) Paris, Albin Miched.

- N'GANDU P., N., (1992) Lillérarures et écritures en langues africaines, Paris, L'llarmattan.

- RABEMANANJARA, J., (1986) Le Devoir, Comores, 21 juin.

- RÉGiS, A. (1992), Liltérature franco-antillaise, (Haïti, Guadeloupe ot Martinique) Paris, Khartala.

- SENGHOR, L.S.. (1964) Liberté 1: Négritude et humanisme, París, Le Seuil. (L'Histoire Immédiate).

- Sengihor, L.S., (1949) Anthologic de la nouvelle poésie nègre el malgache de langue française; (1977) París. P.U.F.

-SIENGHIOR, L.S., (1964) Liberté 2: Nation et voie africaine du socialisme, París, Lo Seuil. (L'Histoire Immédiate).

-SENGIIOR, L.S., (1977) Liberté3: Négritude et civilisation de l'universel, París, Le Seuil.

- TĹTU, M., (1988) La francophonie, Histoire problématique. Perspectives. Prëlace de L.S. Senghor, Paris, Hachette. 